\title{
Surgery of the Primary Tumor Offers Survival Benefits of Breast Cancer with Synchronous Ipsilateral Supraclavicular Lymph Node Metastasis
}

\author{
Qi-tong Chen ${ }^{1} \cdot$ Li-yun Zeng ${ }^{1} \cdot$ Deng-jie Ouyang ${ }^{1} \cdot$ Piao Zhao $^{1} \cdot$ Qiong-yan Zou $^{1}$ • \\ Lei Pei ${ }^{1} \cdot \mathrm{Na} \mathrm{Luo}^{1} \cdot$ Wen-jun $\mathrm{Yi}^{1}$
}

Published online: 26 November 2019

(C) The Author(s) 2019

\begin{abstract}
Background Controversy exists around the locoregional management of the primary tumor for breast cancer associated with synchronous ipsilateral supraclavicular lymph node metastasis (sISLM) due to the rarity of the disease and limited available data. This study aimed to compare outcomes of patients in the Surveillance, Epidemiology, and End Results (SEER) database with sISLM who underwent surgical resection and radiation of the primary tumor with those who did not. Methods This population-based retrospective study included breast cancer patients with sISLM without distant metastases from 2004 to 2016 in the SEER database. In this study, patients had been stratified by operative management, and propensity score matching (PSM) had been successfully applied.

Results A total of 1172 breast cancer patients with sISLM were included in the study: $863(73.6 \%)$ of patients underwent the primary tumor resection, and 309 (26.4\%) patients did not undergo surgery. The median survival time in the surgery group was longer compared to the nonsurgery group in the overall cohort and the PSM cohort. We concluded that the primary tumor resection was associated with improved survival. Subgroup analysis further demonstrated that local surgery was not inferior to radical surgery.

Conclusion For selected breast cancer patients with sISLM, surgery is a promising local intervention which may improve the survival.
\end{abstract}

\section{Introduction}

The incidence of breast cancer with ipsilateral supraclavicular lymph node metastasis (ISLM) without distant metastasis is as low as 1-4\% [1-3]. Two types of ISLM can

Qi-tong Chen and Li-yun Zeng have contributed equally to this work.

Electronic supplementary material The online version of this article (https://doi.org/10.1007/s00268-019-05293-4) contains supplementary material, which is available to authorized users.

Wen-jun Yi

yiwenjun@csu.edu.cn

1 Department of General Surgery, the Second Xiangya Hospital, Central South University, No. 139 Renmin Road, Changsha 410011, China be identified in breast cancer, synchronous ISLM (sISLM) and metachronous ISLM (mISLM) [4]. sISLM is defined as ISLM at the primary diagnosis of breast cancer (T1-4 N3c M0), and mISLM as the occurrence of supraclavicular lymph node metastasis after the initial diagnosis and treatment of breast cancer.

In the 5th edition of the AJCC TNM staging system, breast cancer with the classification of SISLM was modified from N3 to M1 due to its poor outcome and developing distant metastasis within 1 year $[5,6]$. Soon after that, in the 6th edition of the AJCC TNM staging system, breast cancer with sISLM, which was no longer regarded as distant metastasis, was reclassified as stage IIIC (N3c) instead of stage IV and it has maintained the IIIC (N3c) classification to date [7-9]. 
Despite the low incidence, there has always been significant controversy about the local treatment, especially surgery, of the primary tumor site of breast cancer with sISLM. Fan et al. [4] demonstrated that the primary tumor size and radiotherapy after surgery, not including surgery itself, were independent prognostic factors for sISLM. Chen et al. [10] found that young age and the surgical removal of the primary tumor and supraclavicular nodes after sISLM were associated with a significantly better prognosis and survival. Besides, a retrospective study in Japan showed that local-regional therapy, including surgery and radiation, was incapable of reversing the poor prognosis of sISLM breast cancer patients [11]. Breast surgeons tend to perform the primary tumor and lymph node dissection in patients with newly diagnosed SISLM [12]. Currently, whether breast cancer patients with sISLM can benefit from the primary tumor resection remains debatable.

Hence, our study aimed to evaluate the survival benefit of surgery of the primary lesion in breast cancer patients with sISLM based on the data from the Surveillance, Epidemiology, and End Results (SEER) database. Therefore, we retrospectively analyzed the data of 1172 patients from the SEER database to evaluate the main demographic and clinicopathological characteristics affecting prognosis. Our study provides a more in-depth and comprehensive understanding of the clinical features of breast cancer with sISLM and attempts to obtain more evidence to form a theoretical basis for surgery treatment.

\section{Patients and methods}

\section{Data source and cohort selection}

Data were acquired from the SEER database between January 1, 2004, and December 31, 2016, because the 6th AJCC TNM staging system was adopted by SEER starting in 2003. We extracted the data for all cases that were initially diagnosed as malignant primary breast cancer, and multiple primary malignant tumors were excluded. A total of 638,902 patients who were diagnosed with the primary breast cancer between January 1, 2004, and December 31, 2016, were used for analysis in this study. Breast cancer patients who did not have N3c stage disease or who had distant metastasis were excluded. After these steps, we excluded patients who were male or for whom data were unavailable for some critical variables. The follow-up time of the patients was from breast cancer diagnosis until death or the end of the follow-up period. Finally, 1172 female patients who were diagnosed with sISLM (stage N3c but not M1) were included in the analysis (S.Fig. 1).
The SEER is a freely available database [13], and the data released by the SEER database do not require informed patient consent, as cancer is a reportable disease in the USA. The original data in this study were downloaded from the SEER Web site server (https://seer.cancer. gov/data/) via the SEER*Stat software version 8.3.5 in the client-server model.

\section{Variables}

The following demographic and clinicopathological characteristics of N3c stage patients before and after PSM were included in the analysis process (Table 1): age at diagnosis, race, marital status, laterality, histologic type, tumor differentiation grade, $\mathrm{T}$ stage based on the Derived AJCC Stage Group (6th) [14], estrogen receptor (ER) status, progesterone receptor (PR) status, HER2 status, molecular subtype, surgery, radiotherapy, and chemotherapy. Patients were divided into two major subgroups: no surgery and surgery, which could be divided again into the local surgery and radical surgery subgroups (Table 2). The SEER registry provided hormone receptor (HR) information for each patient. Specifically, ER, PR, and HER2 status were included as positive, negative, and undetermined status. A major subset of the patients' HER2 status in this cohort was unavailable because the HER2 status data were collected by SEER starting in 2010. For radiation, due to the data availability of the SEER database, the extent of the radiation fields is not known. Specifically, it is unclear whether the radiation included the SISLM as well.

\section{Propensity score matching (PSM)}

This study was a retrospective and observational study, so the surgery assignment was not random. Some significant covariates of the patients in the active treatment and control groups were heterogeneous and possibly affected the outcomes. Therefore, we further compared the survival rate between the surgery and nonsurgery cohorts by using $1: 1$ nearest-neighbor matching, setting the caliper as 0.02 . The PSM process was applied to minimize the selection bias and to approximately balance the baseline covariates with the analytic settings between groups [15].

\section{Statistical analysis}

Using the Chi-square test, we compared patient characteristics between the surgery and nonsurgery patients. Overall survival (OS) was defined as the time from diagnosis to death from any cause, and disease-specific survival (DSS) was determined based on the date of initial diagnosis to the date of disease-related death. OS and DSS were the primary endpoints of this study. Kaplan-Meier analysis 
Table 1 Baseline characteristics of female patients with sISLM

\begin{tabular}{|c|c|c|c|c|c|c|c|c|}
\hline \multirow[t]{2}{*}{ Category } & \multicolumn{4}{|c|}{ Before propensity score matching } & \multicolumn{4}{|c|}{ After propensity score matching } \\
\hline & $\begin{array}{l}\text { No. of } \\
\text { patients }(\%)\end{array}$ & Surgery $(\%)$ & $\begin{array}{l}\text { Nonsurgery } \\
(\%)\end{array}$ & $P$ value & $\begin{array}{l}\text { No. of } \\
\text { patients }(\%)\end{array}$ & Surgery $(\%)$ & $\begin{array}{l}\text { Nonsurgery } \\
(\%)\end{array}$ & $P$ value \\
\hline \multicolumn{9}{|l|}{ Age } \\
\hline$\leqq 35$ & $74(6.3 \%)$ & $62(7.2 \%)$ & $12(3.9 \%)$ & & $22(4.7 \%)$ & $11(4.7 \%)$ & $11(4.7 \%)$ & \\
\hline $36-45$ & $191(16.3 \%)$ & $159(18.4 \%)$ & $32(10.4 \%)$ & & $57(12.3 \%)$ & $31(13.4 \%)$ & $26(11.2 \%)$ & \\
\hline $46-55$ & $336(28.7 \%)$ & $262(30.4 \%)$ & $74(23.9 \%)$ & $<0.001$ & $130(28 \%)$ & $67(28.9 \%)$ & $63(27.2 \%)$ & 0.592 \\
\hline $56-65$ & $292(24.9 \%)$ & $221(25.6 \%)$ & $71(23 \%)$ & & $113(24.4 \%)$ & $60(25.9 \%)$ & $53(22.8 \%)$ & \\
\hline$>65$ & $279(23.8 \%)$ & $159(18.4 \%)$ & $120(38.8 \%)$ & & $142(30.6 \%)$ & $63(27.2 \%)$ & $79(34.1 \%)$ & \\
\hline \multicolumn{9}{|l|}{ Race } \\
\hline White & $835(71.2 \%)$ & $628(72.8 \%)$ & $207(67 \%)$ & & $324(69.8 \%)$ & $164(70.7 \%)$ & $160(69 \%)$ & \\
\hline Black & $232(19.8 \%)$ & $162(18.8 \%)$ & $70(22.7 \%)$ & $\mathbf{0 . 0 2 7}$ & $93(20 \%)$ & $45(19.4 \%)$ & $48(20.7 \%)$ & 0.137 \\
\hline Other & $96(8.2 \%)$ & $70(8.1 \%)$ & $26(8.4 \%)$ & & $42(9.1 \%)$ & $23(9.9 \%)$ & $19(8.2 \%)$ & \\
\hline Unknown & $9(0.8 \%)$ & $3(0.3 \%)$ & $6(1.9 \%)$ & & $5(1.1 \%)$ & $0(0 \%)$ & $5(2.2 \%)$ & \\
\hline \multicolumn{9}{|l|}{ Marriage } \\
\hline Single & $258(22 \%)$ & $183(21.2 \%)$ & $75(24.3 \%)$ & & $110(23.7 \%)$ & $55(23.7 \%)$ & $55(23.7 \%)$ & \\
\hline Married & $573(48.9 \%)$ & $453(52.5 \%)$ & $120(38.8 \%)$ & $<0.001$ & $199(42.9 \%)$ & $103(44.4 \%)$ & $96(41.4 \%)$ & 0.857 \\
\hline DSW & $298(25.4 \%)$ & $200(23.2 \%)$ & $98(31.7 \%)$ & & $138(29.7 \%)$ & $65(28 \%)$ & $73(31.5 \%)$ & \\
\hline Unknown & $43(3.7 \%)$ & $27(3.1 \%)$ & $16(5.2 \%)$ & & $17(3.7 \%)$ & $9(3.9 \%)$ & $8(3.4 \%)$ & \\
\hline \multicolumn{9}{|l|}{ Laterality } \\
\hline Left & $658(56.1 \%)$ & $490(56.8 \%)$ & $168(54.4 \%)$ & & $249(53.7 \%)$ & $124(53.4 \%)$ & $125(53.9 \%)$ & \\
\hline Right & $503(42.9 \%)$ & $373(43.2 \%)$ & $130(42.1 \%)$ & $<0.001$ & $211(45.5 \%)$ & $108(46.6 \%)$ & $103(44.4 \%)$ & 0.127 \\
\hline Both sides & $11(0.9 \%)$ & $0(0 \%)$ & $11(3.6 \%)$ & & $4(0.9 \%)$ & $0(0 \%)$ & $4(1.7 \%)$ & \\
\hline \multicolumn{9}{|l|}{ Histologic type } \\
\hline Ductal carcinoma & $846(72.2 \%)$ & $655(75.9 \%)$ & $191(61.8 \%)$ & & $320(69 \%)$ & $156(67.2 \%)$ & $164(70.7 \%)$ & \\
\hline Lobular carcinoma & $137(11.7 \%)$ & $114(13.2 \%)$ & $23(7.4 \%)$ & $<0.001$ & $48(10.3 \%)$ & $31(13.4 \%)$ & $17(7.3 \%)$ & 0.097 \\
\hline Other & $189(16.1 \%)$ & $94(10.9 \%)$ & $95(30.7 \%)$ & & $96(20.7 \%)$ & $45(19.4 \%)$ & $51(22 \%)$ & \\
\hline \multicolumn{9}{|l|}{ Grade } \\
\hline I-II & $272(23.2 \%)$ & $219(25.4 \%)$ & $53(17.2 \%)$ & & $99(21.3 \%)$ & $53(22.8 \%)$ & $46(19.8 \%)$ & \\
\hline III-IV & $746(63.7 \%)$ & $576(66.7 \%)$ & $170(55 \%)$ & $<0.001$ & $286(61.6 \%)$ & $143(61.6 \%)$ & $143(61.6 \%)$ & 0.573 \\
\hline Unknown & $154(13.1 \%)$ & $68(7.9 \%)$ & $86(27.8 \%)$ & & $79(17 \%)$ & $36(15.5 \%)$ & $43(18.5 \%)$ & \\
\hline \multicolumn{9}{|l|}{ T Stage } \\
\hline $\mathrm{T} 1-\mathrm{T} 2$ & $505(43.1 \%)$ & $414(48 \%)$ & $91(29.4 \%)$ & & $166(35.8 \%)$ & $91(39.2 \%)$ & $75(32.3 \%)$ & \\
\hline T3-T4 & $600(51.2 \%)$ & $421(48.8 \%)$ & $179(57.9 \%)$ & $<0.001$ & $265(57.1 \%)$ & $124(53.4 \%)$ & $141(60.8 \%)$ & 0.264 \\
\hline Unknown & $67(5.7 \%)$ & $28(3.2 \%)$ & $39(12.6 \%)$ & & $33(7.1 \%)$ & $17(7.3 \%)$ & $16(6.9 \%)$ & \\
\hline \multicolumn{9}{|l|}{ ER } \\
\hline Positive & $578(49.3 \%)$ & $428(49.6 \%)$ & $150(48.5 \%)$ & & $227(48.9 \%)$ & $114(49.1 \%)$ & $113(48.7 \%)$ & \\
\hline Negative & $549(46.8 \%)$ & $417(48.3 \%)$ & $132(42.7 \%)$ & $<0.001$ & $217(46.8 \%)$ & $107(46.1 \%)$ & $110(47.4 \%)$ & 0.884 \\
\hline Unknown & $45(3.8 \%)$ & $18(2.1 \%)$ & $27(8.7 \%)$ & & $20(4.3 \%)$ & $11(4.7 \%)$ & $9(3.9 \%)$ & \\
\hline \multicolumn{9}{|l|}{ PR } \\
\hline Positive & $428(36.5 \%)$ & $320(37.1 \%)$ & $108(35 \%)$ & & $161(34.7 \%)$ & $80(34.5 \%)$ & $81(34.9 \%)$ & \\
\hline Negative & $702(59.9 \%)$ & $529(61.3 \%)$ & $173(56 \%)$ & $<0.001$ & $283(61 \%)$ & $142(61.2 \%)$ & $141(60.8 \%)$ & 0.995 \\
\hline Unknown & $42(3.6 \%)$ & $14(1.6 \%)$ & $28(9.1 \%)$ & & $20(4.3 \%)$ & $10(4.3 \%)$ & $10(4.3 \%)$ & \\
\hline \multicolumn{9}{|l|}{ HER-2 } \\
\hline Positive & $236(20.1 \%)$ & $189(21.9 \%)$ & $47(15.2 \%)$ & & $85(18.3 \%)$ & $46(19.8 \%)$ & $39(16.8 \%)$ & \\
\hline Negative & $409(34.9 \%)$ & $290(33.6 \%)$ & $119(38.5 \%)$ & $<0.001$ & $165(35.6 \%)$ & $73(31.5 \%)$ & $92(39.7 \%)$ & 0.258 \\
\hline Unknown & $34(2.9 \%)$ & $12(1.4 \%)$ & $22(7.1 \%)$ & & $14(3 \%)$ & $6(2.6 \%)$ & $8(3.4 \%)$ & \\
\hline Unavailable & $493(42.1 \%)$ & $372(43.1 \%)$ & $121(39.2 \%)$ & & $200(43.1 \%)$ & $107(46.1 \%)$ & $93(40.1 \%)$ & \\
\hline
\end{tabular}


Table 1 continued

\begin{tabular}{|c|c|c|c|c|c|c|c|c|}
\hline \multirow[t]{2}{*}{ Category } & \multicolumn{4}{|c|}{ Before propensity score matching } & \multicolumn{4}{|c|}{ After propensity score matching } \\
\hline & $\begin{array}{l}\text { No. of } \\
\text { patients (\%) }\end{array}$ & Surgery $(\%)$ & $\begin{array}{l}\text { Nonsurgery } \\
(\%)\end{array}$ & $P$ value & $\begin{array}{l}\text { No. of } \\
\text { patients }(\%)\end{array}$ & Surgery $(\%)$ & $\begin{array}{l}\text { Nonsurgery } \\
(\%)\end{array}$ & $P$ value \\
\hline \multicolumn{9}{|l|}{ Molecular subtype } \\
\hline Luminal A & $233(19.9 \%)$ & $170(19.7 \%)$ & $63(20.4 \%)$ & & $92(19.8 \%)$ & $46(19.8 \%)$ & $46(19.8 \%)$ & \\
\hline Luminal B & $134(11.4 \%)$ & $109(12.6 \%)$ & $25(8.1 \%)$ & & $51(11 \%)$ & $30(12.9 \%)$ & $21(9.1 \%)$ & \\
\hline HER-2-enriched & $100(8.5 \%)$ & $79(9.2 \%)$ & $21(6.8 \%)$ & 0.040 & $33(7.1 \%)$ & $16(6.9 \%)$ & $17(7.3 \%)$ & 0.129 \\
\hline TNBC & $176(15 \%)$ & $120(13.9 \%)$ & $56(18.1 \%)$ & & $73(15.7 \%)$ & $27(11.6 \%)$ & $46(19.8 \%)$ & \\
\hline Unknown & $529(45.1 \%)$ & $385(44.6 \%)$ & $144(46.6 \%)$ & & $215(46.3 \%)$ & $113(48.7 \%)$ & $102(44 \%)$ & \\
\hline \multicolumn{9}{|l|}{ Radiation } \\
\hline Radiation & $677(57.8 \%)$ & $607(70.3 \%)$ & $70(22.7 \%)$ & $<0.001$ & $148(31.9 \%)$ & $82(35.3 \%)$ & $66(28.4 \%)$ & 0.111 \\
\hline Nonradiation & $495(42.2 \%)$ & $256(29.7 \%)$ & $239(77.3 \%)$ & & $316(68.1 \%)$ & $150(64.7 \%)$ & $166(71.6 \%)$ & \\
\hline \multicolumn{9}{|l|}{ Chemotherapy } \\
\hline Chemotherapy & $1036(88.4 \%)$ & $817(94.7 \%)$ & $219(70.9 \%)$ & & $397(85.6 \%)$ & $203(87.5 \%)$ & $194(83.6 \%)$ & \\
\hline Nonchemotherapy & $136(11.6 \%)$ & $46(5.3 \%)$ & $90(29.1 \%)$ & $<0.001$ & $67(14.4 \%)$ & $29(12.5 \%)$ & $38(16.4 \%)$ & 0.235 \\
\hline Total & 1172 & $863(73.6 \%)$ & $309(26.4 \%)$ & & 464 & $232(50.0 \%)$ & $232(50.0 \%)$ & \\
\hline
\end{tabular}

SISLM synchronous ipsilateral supraclavicular lymph node metastasis, $D S W$ divorced/separated/widowed, $E R$ estrogen receptor, $P R$ progesterone receptor, $T N B C$ triple-negative breast cancer

Table 2 Type of surgery for breast cancer patients with sISLM

\begin{tabular}{|c|c|c|}
\hline Category & No. of patients & Percent \\
\hline Local surgery & 335 & 38.82 \\
\hline Partial mastectomy ${ }^{\mathrm{a}}$ & 29 & 3.36 \\
\hline Lumpectomy or excisional biopsy & 121 & 14.02 \\
\hline Reexcision of the biopsy site for gross or microscopic residual disease & 30 & 3.48 \\
\hline Segmental mastectomy & 18 & 2.09 \\
\hline Subcutaneous mastectomy ${ }^{\mathrm{b}}$ & 8 & 0.93 \\
\hline Total (simple) mastectomy ${ }^{\mathrm{c}}$ & 129 & 14.95 \\
\hline Radical surgery & 528 & 61.18 \\
\hline Modified radical mastectomy ${ }^{\mathrm{d}}$ & 511 & 59.21 \\
\hline Radical mastectomy ${ }^{\mathrm{e}}$ & 16 & 1.85 \\
\hline Extended radical mastectomy ${ }^{\mathrm{f}}$ & 1 & 0.12 \\
\hline Total & 863 & 100.00 \\
\hline
\end{tabular}

${ }^{a}$ Removal of the gross primary tumor and some of the breast tissue (breast-conserving or breast-preserving surgery)

${ }^{b}$ Removal of breast tissue without the nipple and areolar complex or overlying skin

${ }^{\mathrm{c}}$ Removal of all breast tissue, the nipple, and the areolar complex. An axillary dissection is not done

${ }^{\mathrm{d}}$ Removal of all breast tissue, the nipple, the areolar complex, and variable amounts of breast skin in continuity with the axilla. The specimen may or may not include a portion of the pectoralis major muscle

${ }^{\mathrm{e}}$ Removal of breast tissue, nipple, areolar complex, variable amount of skin, pectoralis minor, and/or pectoralis major, as well as en bloc axillary dissection

${ }^{\mathrm{f}}$ Removal of breast tissue, nipple, areolar complex, variable amounts of skin, pectoralis minor, and/or pectoralis major, as well as removal of internal mammary nodes and en bloc axillary dissection

and the log-rank test were used to estimate OS and DSS before and after PSM. Cox proportional hazard regression was used to identify a hazard ratio (HR), and a corresponding 95\% confidence interval (CI) was calculated. A forest plot was utilized to conduct a subgroup analysis comparing the survival rate. All data were examined using
SPSS statistical software (version 22.0; IBM Corporation). All statistical tests were two-sided, and the statistical significance level was set at $P<0.05$. 
Table 3 A 3-, 5-, and 10-year survival of patients with sISLM

\begin{tabular}{|c|c|c|c|c|c|c|}
\hline & \multicolumn{3}{|l|}{ OS } & \multicolumn{3}{|l|}{ DSS } \\
\hline & 3 Years $(\%)$ & 5 Years $(\%)$ & 10 Years $(\%)$ & 3 Years $(\%)$ & 5 Years $(\%)$ & 10 Years $(\%)$ \\
\hline Nonsurgery & 34.7 & 23.9 & 14.0 & 38.8 & 28.5 & 17.9 \\
\hline Surgery & 61.9 & 51.2 & 38.9 & 64.7 & 54.8 & 45.0 \\
\hline Local surgery & 63.1 & 54.8 & 42.1 & 65.8 & 58.3 & 48.7 \\
\hline Radical surgery & 61.1 & 49.2 & 37.4 & 64.0 & 52.9 & 43.1 \\
\hline
\end{tabular}

sISLM synchronous ipsilateral supraclavicular lymph node metastasis, $O S$ overall survival, DSS disease-specific survival

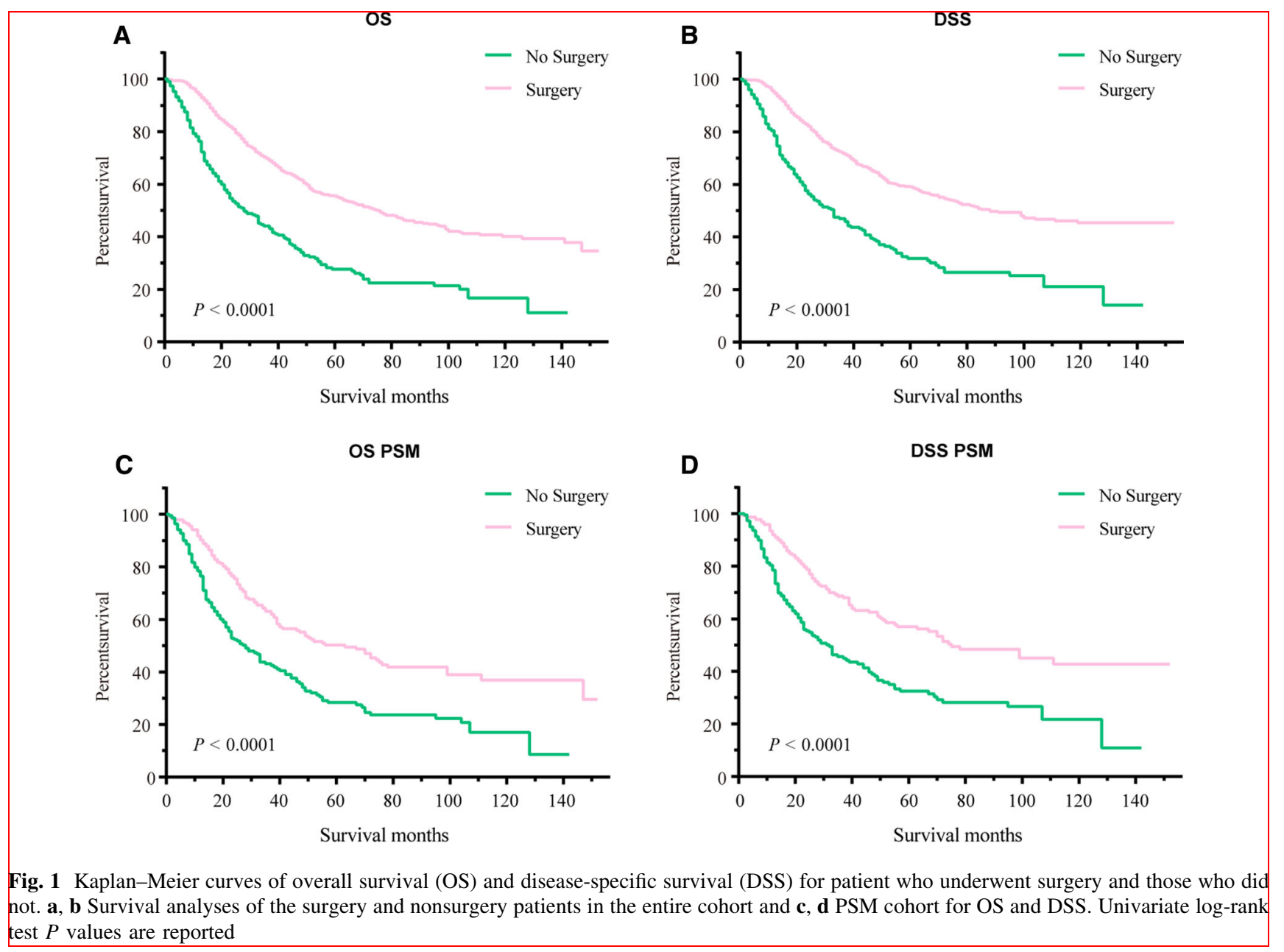

\section{Results}

\section{Baseline characteristics of the patients before and after PSM}

In the present study, the patient characteristics are presented in Table 1 Based on the eligibility criteria, a cohort of 1172 patients was enrolled in the present study. The median age of the patients was 55 (range 22-98) years. The surgery and nonsurgery cohorts included 863 (73.6\%) and $309(26.4 \%)$ patients, respectively. After propensity score matching, a total of 464 patients (surgery 232 (50.0\%) versus nonsurgery $232(50.0 \%)$ ) were matched. All variables were properly balanced between these two groups. The baseline characteristics of the patients before and after propensity score matching are summarized in Table 1 . Patients undergoing surgery could be subdivided into local surgery $(n=335,38.8 \%)$ and radical surgery $(n=528$, $61.2 \%$ ) subgroups, as defined in Table 2. 

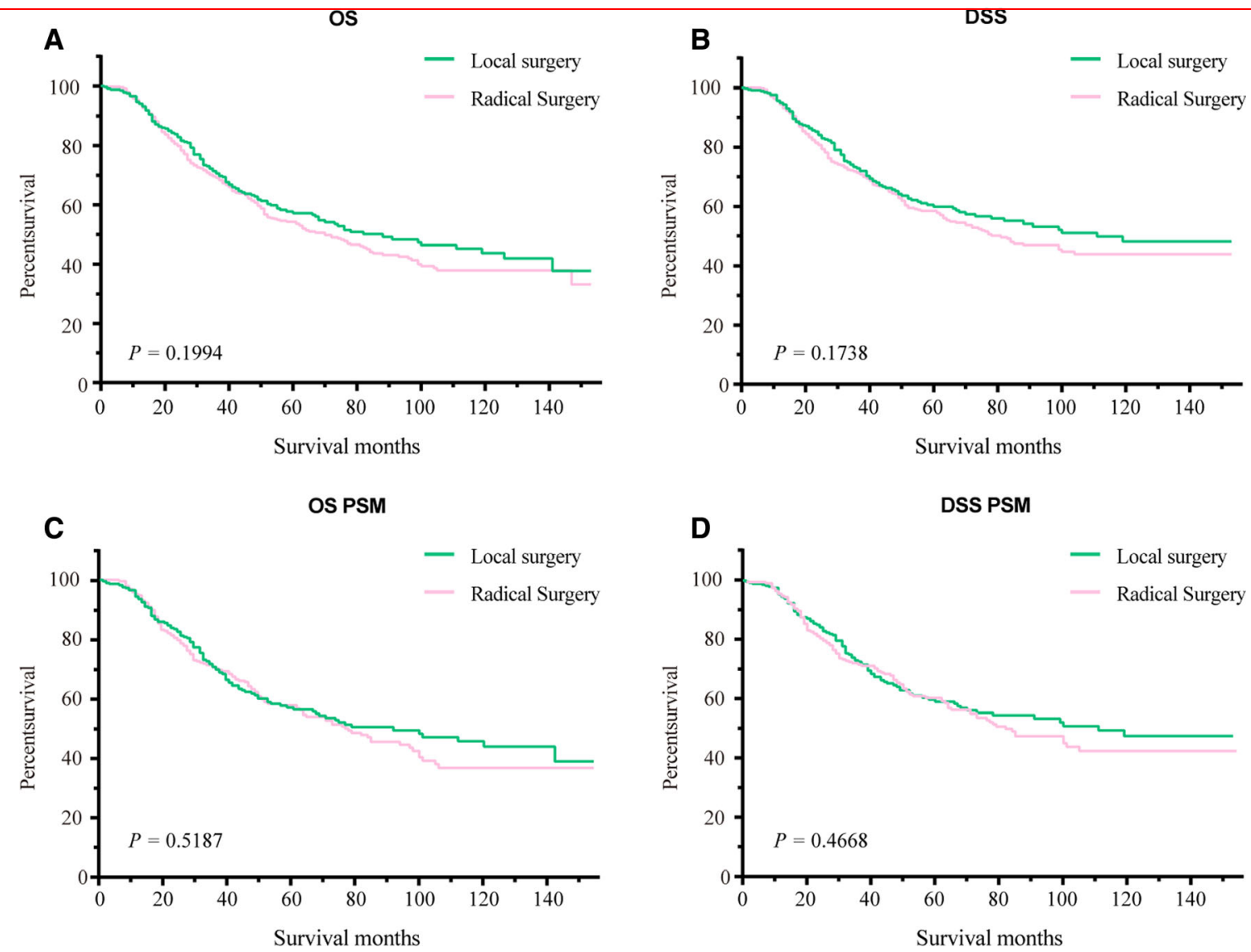

Fig. 2 Kaplan-Meier curves of overall survival (OS) and disease-specific survival (DSS) for patients who underwent local surgery and radical surgery. a, b Survival analyses of the local surgery and radical surgery patients in the entire cohort and c, d PSM cohort for OS and DSS. Univariate log-rank test $P$ values are reported

\section{Survival analysis of breast cancer patients with SISLM}

OS and DSS of the surgery group were 61.9 and $64.7 \%$ at 3 years, 51.2 and $54.8 \%$ at 5 years, and 38.9 and $45.0 \%$ at 10 years. Comparatively, OS and DSS of nonsurgery group were 34.7 and $38.8 \%$ at 3 years, 23.9 and $28.5 \%$ at 5 years, and 14.0 and $17.9 \%$ at 10 years (Table 3). The median OS for the surgery group and nonsurgery group was 75.27 months and 28.50 months, respectively. Also, the median DSS for the surgery group and nonsurgery group was 90.16 months and 32.31 months, respectively. Kaplan-Meier survival curves with the log-rank test for OS and DSS were performed based on the surgery variables, which are presented in Fig. 1. The survival analyses indicated that the surgery patients had a significantly better OS $(P<0.0001)$ and DSS $(P<0.0001)$ compared with those of nonsurgery patients (Fig. 1a, b). The OS and DSS differences persisted in the PSM cohort (Fig. 1c, d OS $P<0.0001$, DSS $P<0.0001)$.
Additionally, OS and DSS of the local surgery group were 63.1 and $65.8 \%$ at 3 years, 54.8 and $58.3 \%$ at 5 years, and 42.1 and $48.7 \%$ at 10 years. Comparatively, OS and DSS of the radical surgery group were 61.1 and $64.0 \%$ at 3 years, 49.2 and $52.9 \%$ at 5 years, and 37.4 and $43.1 \%$ at 10 years (Table 3 ). The median OS for the local surgery group and the radical surgery group was 87.29 months and 69.85 months, respectively. Also, the median DSS for the local surgery group and the radical surgery group was 114.60 months and 79.54 months, respectively. There was no significant difference for the OS $(P=0.1994)$ and DSS $(P=0.1738)$ between the patients who underwent local surgery and those who underwent radical surgery (Fig. 2a, b). PSM between the local surgery group and the radical surgery group was performed (specific data are not shown.) Also, no significant differences were found between these two groups for OS $(P=0.5187)$ and DSS $(P=0.4668)$ after PSM (Fig. 2c, d).

Moreover, Kaplan-Meier curves for OS and DSS were generated based on the surgery and radiation variables, which are presented in Fig. 3. The Kaplan-Meier analyses 


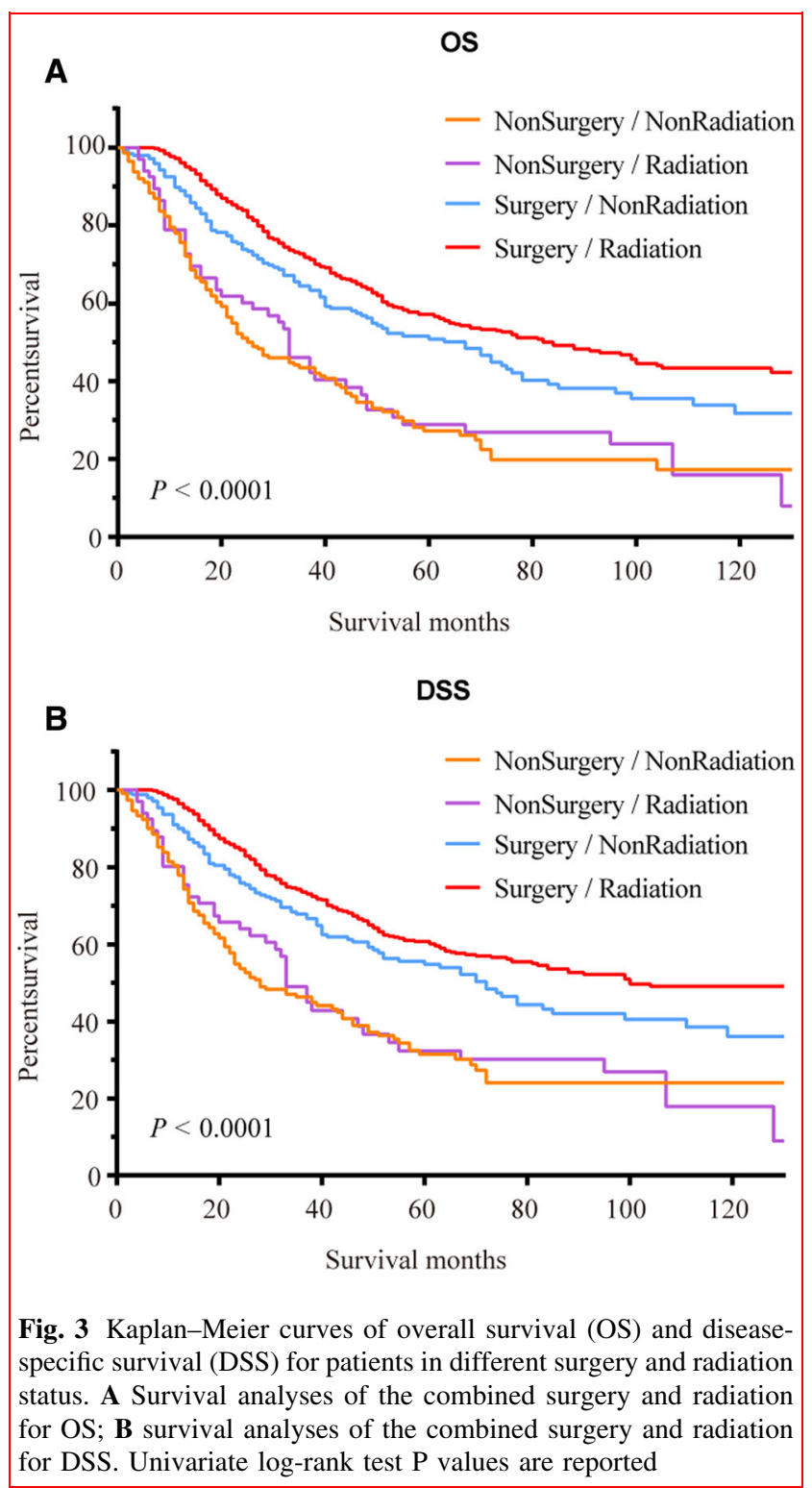

indicated that surgery-treated patients had a remarkably better OS and DSS than nonsurgery group $(P<0.0001)$ (Fig. 3a, b). There was no significant difference in nonsurgery patients for the OS and DSS between the radiation and nonradiation groups (OS $P=0.5593$, DSS $P=0.6967$, S.Fig. 2a, b). There was a significant difference for the OS and DSS in surgery patients between the radiation and nonradiation (OS $P=0.0078$, DSS $P=0.0101$ S.Fig. 2C \& 2D).

\section{Subgroup analyses}

To assess whether the distribution of the subject characteristics was consistent, two subgroup analyses of overall survival and disease-specific survival were performed in prespecified subgroups using a forest plot (Figs. 4, 5). The two prespecified stratification factors were the presence or absence of surgical treatment (subgroup analyses A, Fig. 4), and between local surgery and radical surgery (subgroup analyses B, Fig. 5).

Among the 1172 patients included in subgroup analysis A, for OS, the forest plot indicated that there was a significant difference when the efficacy of surgery to no surgery was compared. Most variables showed that surgery benefited the patients with sISLM compared to no surgery (Fig. 4). Explicitly speaking, no statistical difference was observed in unknown marital status and nonchemotherapy subgroup for OS, unknown marital status, lobular carcinoma, unknown HER-2 status, and luminal B molecular subtype for DSS (Fig. 4).

In the subgroup analysis B involving 863 patients, the forest plot showed that the efficacy of local surgery and radical surgery was similar (Fig. 5). There were statistical differences in the 36-45 age subgroup and ER-positive status subgroup for OS, indicating that local surgery offers less hazard ratio than radical surgery. Similarly, in the 36-45 age subgroup, the unknown marital status subgroup, and ER-positive status subgroup, patients who underwent local surgery have a better prognosis for DSS. Nevertheless, most of the other subgroups did not show statistical differences. It may indicate that, for sISLM patients, compared with radical surgery, local surgery has an equivalent prognostic value (Fig. 5).

\section{Discussion}

In recent decades, the classification of patients with SISLM in the AJCC TNM staging system has been revised several times due to the different prognostic conclusions drawn from various studies $[5-7,16,17]$. These findings also raise questions about the most appropriate local treatment for breast cancer patients with sISLM. The most heated debate is whether the implementation of the surgery on the primary lesion affects the patient's prognosis. A meta-analysis published in 2015 suggests that the prognosis for breast cancer patients with ipsilateral ISLM is similar to patients with stages IIIb/c disease and different from patients with stage IV disease. The authors also proposed that radical, instead of palliative therapy, seems more plausible for these patients [18]. Other studies suggested that breast cancer women with sISLM should be considered as a local-regional disease, and aggressive local therapy may indeed improve outcomes [19, 20]. However, studies found that the locoregional surgical therapy after the diagnosis sISLM did not correlate with survival [4, 21].

In our present study, we evaluated 1172 primary breast cancer patients with sISLM from the SEER database between 2004 and 2016. In Kaplan-Meier curve analysis, 


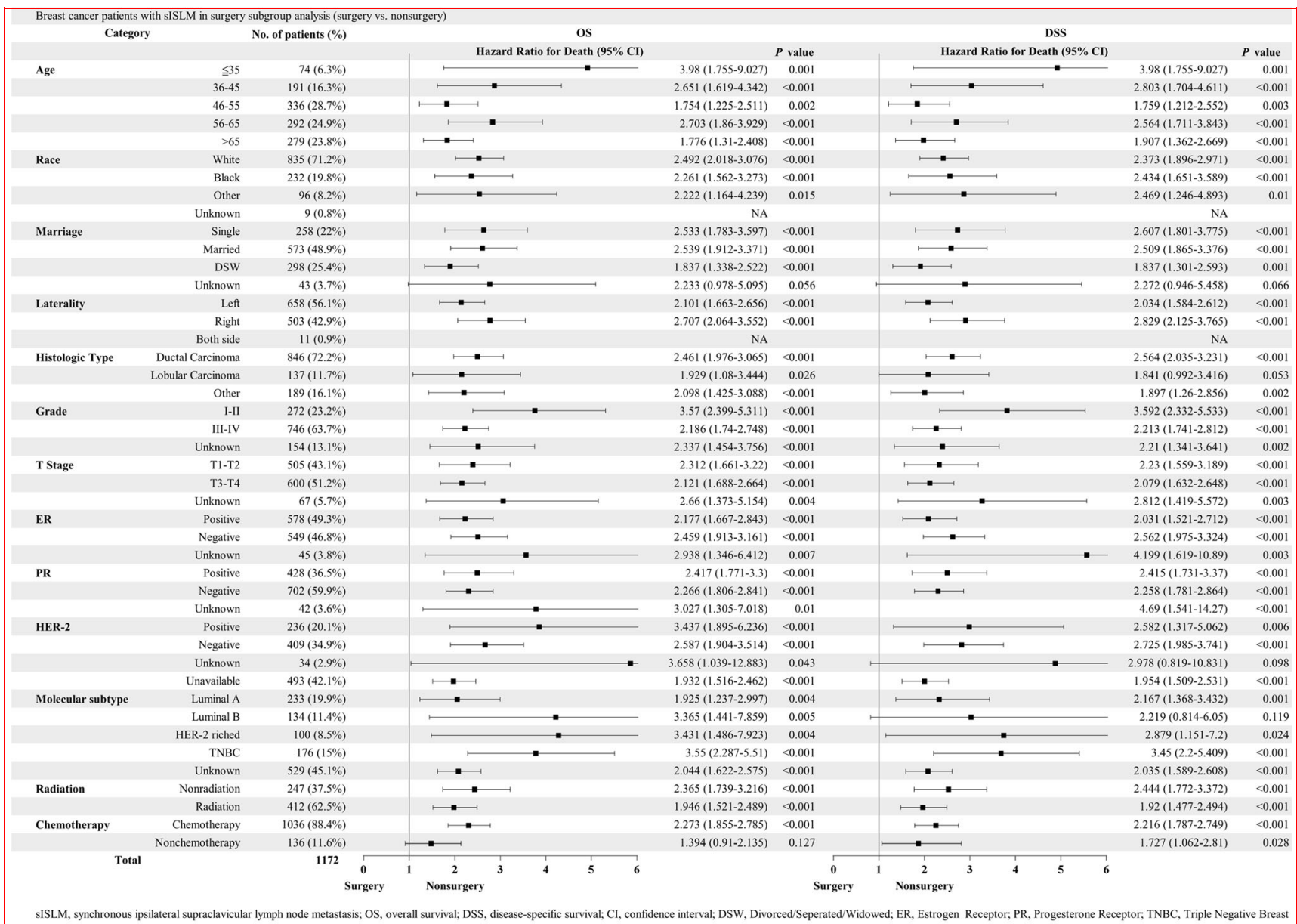

Fig. 4 Forest plot for patients with sISLM in the subgroup analysis A (surgery vs. nonsurgery). Hazard ratio (HR) with 95\% confidence interval (CI) for death in the overall survival (OS) and disease-specific survival (DSS) of patients with sISLM who did and did not undergo surgery. $\mathrm{P}$ values of the Cox proportional hazard regression are reported

forest plots of subgroup analyses for OS and DSS indicated that surgery was a significant prognostic factor for sISLM patients (Figs. 1, 4). Further, the subgroup analysis showed that both local surgery and radical surgery might have an association with improved prognosis (Fig. 5). Moreover, about enhancing N3c patients' survival, the efficacy of local surgery is not inferior to that of radical surgery (Fig. 5). For radiotherapy, one of the most important means of local treatment, there was a significant difference between the radiation and nonradiation groups in surgery patients but not in nonsurgery patients (Fig. 3). These results suggested to our clinicians that, in the face of this specific type of breast cancer, the surgical approach might significantly improve the patient's quality of life and prognosis. Interestingly, local surgery had a similar prognostic effect as that of radical surgery, suggesting that in the clinical setting, a smaller, local treatment would be a better choice.
Retrospective studies including our study are associated with several limitations, such as inability to control for selection bias and lack of information about the administration of systemic therapy response to therapy and sequencing of treatment in patients who get multimodal therapy. Nevertheless, we tried to perform PSM to reduce the adverse effects of the natural bias and increase the objectivity and scientificity of the research. There was an association with surgery and improved prognosis and that a randomized control trial would be required to demonstrate or explore this further.

\section{Conclusion}

In conclusion, for patients with breast cancer with sISLM, surgery is an effective local intervention and the efficacy of local surgery is not inferior to that of radical surgery. The 


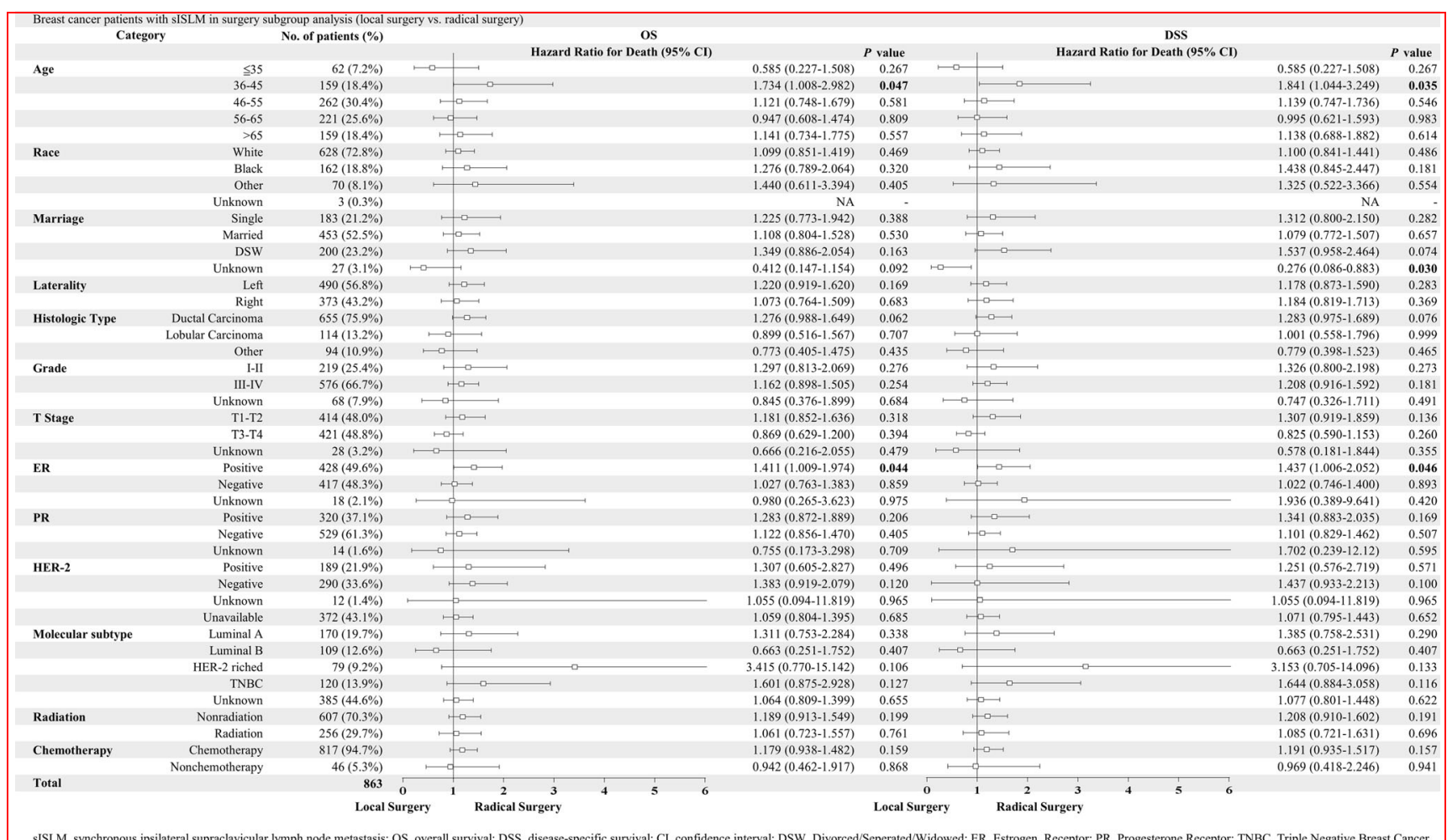

Fig. 5 Forest plot for the patients with sISLM in the subgroup analysis B (local surgery vs. radical surgery). Hazard ratio (HR) with 95\% confidence interval (CI) for death in the overall survival (OS) and disease-specific survival (DSS) of patients with sISLM with local surgery compared with radical surgery. $\mathrm{P}$ values of the Cox proportional hazard regression are reported

principal clinical value of this study is to demonstrate the effectiveness of local interventions in breast cancer patients with sISLM.

Acknowledgements The authors would like to thank the SEER program for providing open access to the database.

Author's contribution QC, NL, and D-JO collected the data; LZ, PZ, and QZ performed the statistical analysis; QC, LZ and PL prepare the manuscript; and WY conceived the study. All authors read and approved the final manuscript.

Data availability The authors declare that the data supporting the findings of this study are available within the article.

\section{Compliance with ethical standards}

Conflict of interest The authors declare that they have no conflict of interest

Open Access This article is distributed under the terms of the Creative Commons Attribution 4.0 International License (http://crea tivecommons.org/licenses/by/4.0/), which permits unrestricted use, distribution, and reproduction in any medium, provided you give appropriate credit to the original author(s) and the source, provide a link to the Creative Commons license, and indicate if changes were made.

\section{References}

1. Chen SC, Chen MF, Hwang TL et al (2002) Prediction of supraclavicular lymph node metastasis in breast carcinoma. Int $\mathrm{J}$ Radiat Oncol Biol Phys 52:614-619

2. Harris EE, Hwang WT, Seyednejad F et al (2003) Prognosis after regional lymph node recurrence in patients with stage I-II breast carcinoma treated with breast conservation therapy. Cancer 98:2144-2151

3. Chavez-MacGregor M, Mittendorf EA, Clarke CA et al (2017) Incorporating tumor characteristics to the American Joint Committee on cancer breast cancer staging system. Oncologist 22:1292-1300

4. Fan Y, Xu B, Liao Y et al (2010) A retrospective study of metachronous and synchronous ipsilateral supraclavicular lymph node metastases in breast cancer patients. Breast 19:365-369

5. Debois JM (1997) The significance of a supraclavicular node metastasis in patients with breast cancer. A literature review. Strahlentherapie und Onkologie : Organ der Deutschen Rontgengesellschaft [et al] 173:1-12

6. Kiricuta IC, Willner J, Kolbl O et al (1994) The prognostic significance of the supraclavicular lymph node metastases in breast cancer patients. Int J Radiat Oncol Biol Phys 28:387-393

7. Brito RA, Valero V, Buzdar AU et al (2001) Long-term results of combined-modality therapy for locally advanced breast cancer with ipsilateral supraclavicular metastases: the University of Texas M.D. Anderson Cancer Center experience. J Clin Oncol 19:628-633 
8. Singletary SE, Allred C, Ashley P et al (2002) Revision of the American Joint Committee on Cancer staging system for breast cancer. J Clin Oncol 20:3628-3636

9. Giuliano AE, Connolly JL, Edge SB, et al (2017) Breast cancermajor changes in the American Joint Committee on Cancer eighth edition cancer staging manual. CA Cancer J Clin 67:290-303

10. Chen SC, Chang HK, Lin YC et al (2006) Prognosis of breast cancer after supraclavicular lymph node metastasis: not a distant metastasis. Ann Surg Oncol 13:1457-1465

11. Ogino T, Komoike Y, Ishitobi M et al (2011) Breast cancer with ipsilateral supraclavicular metastases. Breast J 17:555-557

12. Bisase B, Kerawala C (2012) Survey of UK practice for management of breast cancer metastases to the neck. Ann R Coll Surg Engl 94:484-489

13. Surveillance, Epidemiology and End Results Program. About the SEER Program, 2018. https://seer.cancer.gov/about. Accessed 21 Jan 18

14. Edge SB, Byrd DR, Compton CC et al (2010) American joint committee on cancer staging manual, 7. Springer, New York

15. Pattanayak CW, Rubin DB, Zell ER (2011) Propensity score methods for creating covariate balance in observational studies. Rev Esp Cardiol 64:897-903

16. Olivotto IA, Chua B, Allan SJ et al (2003) Long-term survival of patients with supraclavicular metastases at diagnosis of breast cancer. J Clin Oncol 21:851-854
17. Dellapasqua S, Bagnardi V, Balduzzi A et al (2014) Outcomes of patients with breast cancer who present with ipsilateral supraclavicular or internal mammary lymph node metastases. Clin Breast Cancer 14:53-60

18. Liu XH, Zhang L, Chen B (2015) A meta-analysis of the prognosis in patients with breast cancer with ipsilateral supraclavicular lymph node metastasis versus patients with stage IIIb/c or IV breast cancer. Chronic Dis Transl Med 1:236-242

19. Pedersen AN, Moller S, Steffensen KD et al (2011) Supraclavicular recurrence after early breast cancer: a curable condition? Breast Cancer Res Treat 125:815-822

20. Jung J, Kim SS, Ahn SD et al (2015) Treatment outcome of breast cancer with pathologically proven synchronous ipsilateral supraclavicular lymph node metastases. J Breast Cancer 18:167-172

21. Wu SG, Sun JY, Zhou J et al (2014) The value of radiotherapy in breast cancer patients with isolated ipsilateral supraclavicular lymph node metastasis without distant metastases at diagnosis: a retrospective analysis of Chinese patients. Oncol Targets Ther 7:281-288

Publisher's Note Springer Nature remains neutral with regard to jurisdictional claims in published maps and institutional affiliations. 